\title{
Information \& Communication Technologies in ELT
}

\author{
AbdulMahmoud Idrees Ibrahim \\ P. O. Box 1432, English Language Department, Faculty of Education, Alza'em Alazhari University, Sudan \\ Email: amdid@maktoob.com
}

\begin{abstract}
This paper will address modern technology as an Information and Communication Technologies, which has become possible in our communities since the availability of computers. Moreover, to what extend we can exploit it in education in general and English Language teaching / learning (ELT) in particular, according to our conditions and needs. Information Communication Technologies should be exploited effectively to shift from teacher-centered approach to the student-centered approach in teaching or learning English. As technology has created change in all aspects of society, it is also changing our expectations of what students must learn in order to function in the new world. Students will have to learn programmed materials and to steer through large amounts of information via computer into the web, to master new knowledge with these innovative technologies.
\end{abstract}

Index Terms — information and communication technologies, ELT, learning, informationalism

\section{INTRODUCTION}

The breakthrough of Information and Communication Technologies (ICTs) has utterly shaped our modern life. ICT is the term that is currently used worldwide to describe new technologies which depend mainly on computers nowadays. Even the traditional technologies such as radio, television and telephone are considered as ICTs.

The United Nations Development Programme (UNDP, 2003) defines ICTs as:

'basically information-handling tools- a varied set of goods, applications and services that are used to produce, store, process, distribute and exchange information. They include the 'old' ICTs of radio, television and telephone, and the 'new' ICTs of computers, satellite and wireless technology and the Internet. These different tools are now able to work together, and combine to form our 'networked world' a massive infrastructure of interconnected telephone services, standardized computing hardware, the internet, radio and television, which reaches into every corner of the globe'.

Technological innovation has changed the social, political, economic, and cultural fabric of life since the end of the Cold War (Taylor, 2001). Information and communication technologies (ICTs) have been instrumental in social transformations - from the industrial society of the 20th century to the 'network society' of the new age of 'Informationalism' - where even intercontinental neighbors are now one button-push away (Castells, 1996). Information and communication technologies (ICTs) are a double-edged sword destructive and beneficial to the extreme. Therefore, we have to face this fact and react immediately. We should ask ourselves about its availability and its affordability concerning its cost in our developing countries. In addition, we have to determine its effectiveness and suitability to the different educational contexts.

The Information and Communications Technologies (ICTs) have a vital role in the process of any language teaching and learning. Evidently, no one would deny its contributions to the educational field. Especially, to the teaching and learning of English language they have a considerable influence on the way we teach and the content we deliver. The new ICTs are much faster than the traditional ones and it might give an immediate feedback as well as the instant interaction.

The ICTs are potentially more open and affordable to be owned and operated by schools, universities, private institutions, or even by individuals, who can control the process according to the one's own needs and wants for better controlled outcome and quality.

\section{THE POWER OF ENGLiSH LANGUAGE}

We are teaching English and learning English, but why do we want to teach English, in contrast with other foreign languages? The given answer is that English is the most widespread language in the world. It is difficult to guess exactly how many English speakers there are. However, according to estimation there are more than 350,000,000 native English speakers and more than 400,000,000 speakers of English as a second language or foreign language.

English Language Teaching (ELT) importance is in its steady progress via many means of modern communication technologies and inventions. Graddol (2000) states that in the year 2000 there were about a billion English learners but in the year 2010 the number will be doubled. Moreover he indicates that over $80 \%$ of information which is loaded on 
the Internet is in English language. Amazingly, for the first time in history there are more non-native who use a given language than its native users at all.

The importance of English is not just, in how many people speak it, but in what it is used for. English is the major language of news, internet and information in the world. It is the language of medicine, business and political affairs in some countries, where it has other minor languages. It is the language of science and technology in countries where it is not a native language. Moreover, in the workforce competency in English is required beside the very field of specialization. Therefore, English for us is an evitable language to be taught and learned in our educational institutions if we want to keep in touch with the each other and up-to-date in our information.

\section{INFORMATION \& COMMUNICATION TECHNOLOGIES IN ELT}

Sudanese schools and most of the African schools in general rely on the traditional methods of teaching English as second/foreign language such as the grammar translation method or audio lingual method neglecting genuine opportunity provided by these modern technologies. As consequence for many factors when our students leave the high school students who have studied formal English teaching often remain poor to use the language communicatively (spoken or written) when they encounter authentic situations.

Nowadays, teachers of English around the world prefer some form of communicative teaching and learning, rather than the traditional methods of ELT which dominate the teacher-centered approach and neglect the student' communication skills. The teacher-centered approach depends mainly on the learner's memory and did not care about the authentic use of language. Although, a successful EFL teacher is not necessarily restricted to one method or another, the ICTs have changed the pace of teaching strategies to suit the goals of his materials and the needs of his students. On the other hand ICTs have given the students many opportunities to practice English in and out the classroom. With the help of the modern technologies they have time and freedom to understand, reflect and analyze what have been exposed to.

Moreover, the ICTs put forward an influential base for efficient education. Now, we need the modern technologies for a better blended method of delivery to create apt teaching techniques to enhance the process of learning English language. ICTs are very motivating, because they help the learners to learn the language which is carefully designed to meet the prescribed goals.

\section{THE IMPACTS OF ICTS ON ELT}

No doubt, motivation is the cornerstone in the process of acquiring or learning a foreign language; therefore, learners usually have a positive attitude toward computers. Even though, the modern technologies are double-edged sword, their advantages are acknowledgeable over its pitfalls. No doubt, they have significant, positive impacts on ELT, the following are some them:

\section{A. Availability of the Materials}

ICTs are very stimulating because of the availability of the learning materials whether it is computer-based, in the web or on CDs; therefore, the student can learn at his own pace with a very patient tutor (the machine). Meanwhile, the use of online telecommunications for teaching and learning via the computer in the classroom across the world will consolidate the improvement of different academic skills. The availability of images, animation, audio and video clips they help much more in presenting and practicing new language.

\section{B. Student Attitudes}

ICTs have positive effects on student attitudes toward the language teaching and learning. Students felt more successful in school, were more motivated to learn and have increased self-confidence and self-esteem when using computer-based instruction. This was particularly true when the technology allowed learners to control their own learning.

\section{Autonomy}

Students have the opportunity to choose the element/s of language which they want to focus on meeting their learning strategies or learning styles. Here, the learner-centered approach is supported by these facilities offered by the ICTs while the tradition techniques approaches failed to give such opportunities. The student feels free to practice the language without fear from the others at their own phase and pace.

\section{Authenticity}

ICTs provide authentic learning environment, because the learner can interact with others across the continent are very motivating to the language learners. Confronting such challengeable situations is the touchstone for using the language in authenticity not artificially. The ICTs as tools for learning are very motivational; however, they are very attractive and accessible.

\section{E. Multifaceted Tools}


No doubt, (ICTs) could successfully contribute to two ends: creating a blend of classroom materials and delivering those materials in multiple ways. They facilitate different activities such as testing, doing exercises and performing different pedagogical tasks or games.

\section{F. Help Teachers}

ICTs help the teacher to prepared, produce, store and retrieve their materials easily and swiftly. The availability of different rich texts, different topics, quizzes, exercises help in saving the teacher's time. Despite the opportunities and facilities offered by the modern technologies in assisting better teaching, but they do not replace it. So far, the skillful teacher is the only person who is shouldering the responsibility of delivering and achieving the teaching goals.

\section{G. Student-centered}

ICTs help the student be exposed to language clockwise and definitely they help them to write and edit their work in order to produce a well published work. Likewise, computers encourage students to do extra work outside the classroom, play language games and, hopefully, gain extra exposure to the language and improve their progress in the language and support the student-centered concept. Via the computer and the internet the students will be able to communicate with others in different places.

Moreover, ICTs help the shy or the quiet students who sometimes abstain from asking questions or challenging information to communicate and ask questions. Using modern technologies in the learning environment has been shown to make learning more student-centered and improve the learning process by stimulating teacher/student interaction. Furthermore, ICTs enhance collaborative learning which results in higher self-esteem and student achievement. They promote critical thinking and student-student interaction.

\section{H. ICTs in Self-Assessment}

The examinations generally test the reading and writing skills of the students, totally neglecting the listening and speaking skills, which are indispensable skills for the learners in their future career. The listening capacity can be tested through computer-assisted packages like listening to a dialogue/passage and answering the questions or listening to lectures and then answering short questions or true or false statements. It will enhance their talents for taking international tests because many competitive exams follow such a pattern to test the grasping ability of the students.

\section{SHORTCOMINGS OF ICTS}

Instructors should be aware of modern technologies pitfalls if they want to adopt them in pedagogy. Feenberg (2002) and Yagelski (2005) give their warning for the teachers to study carefully the integration of any newer ICTs into English language arts and literacy teaching as a given advantageous outcomes. The development of new technologies and the decision to integrate them into teaching and learning lives is neither a given conclusion nor following a prearranged route.

Teachers, individually and collectively, have the capacity and the responsibility to influence the development, modification, adoption, and/or rejection of newer technologies. In order to make these critical decisions, they will need to understand not only how to use these technologies, but also the benefits and costs their adoption and integration into English language arts and literacy teaching have the potential to create for teachers, students, and the broader community.

We should not take up such serious issues childishly without thinking of the consequences. Since best practice in teaching requires that teaching must be definite to individual students, classrooms, and communities. Such decisionmaking will require additional research on the classroom at local as well as national levels.

If the teachers and the students haven't got sufficient training to use the new technologies effectively, the process will be frustrating and time consuming.

The quality of programs has not yet reached the level of assessing the users' natural spoken language or the appropriateness of use in the context of the situation.

\section{DESIGNING AND DELIVERING MATERIALS VIA ICTS}

Evidently, learning materials designed and delivered by modern technologies add quality and value to the teaching/learning environment. They should help develop basic thought processes such as critical thinking, analysis, and problem solving. The skillful instructor knows how to get the maximum benefits from these technologies in during the period or course limited life time.

New materials delivered via the Internet that help with the repetition needed for developing reading, writing, and listening in English can reduce hard work for educators and can be entertaining for both the teacher and the learner. Actually, modern technologies can facilitate and motivate the teaching and learning process.

\section{PEDAGOGICAL IMPLICATIONS OF ICTS}

To obtain a better benefit from the potentials of the ICTs there should be the following: 
a. Every classroom should be equipped at least with a computer and a data show projector to enable the teacher to present the new lesson effectively.

b. There should be a website for the class designed deliberately for pedagogical purposes. Teachers can exploit this site for assigning exercises, homework and in turn the students can respond to the instruction and the feedback would be immediately via the machine.

c. As the feedback is immediate, the learners can identify their strengths and weaknesses and improve on them. As learner autonomy gets momentum, they facilitate individualizing curriculum, permitting them to dictate the pace of learning and widen the sources of information in the required area.

d. It has been widely recognized that connecting the power of ICTs for learning purposes requires that appropriate learning strategies be developed that harmonize effectiveness in learning with the technology role. This recognition underpins the UfI/National Grid for Learning relationship, and a general interest in fostering innovation in learning strategies (Kearns \& Papadopoulos 2000:77).

e. Every student should have an email and he should use his email in sending his assignment and any enquiries to his tutor.

f. The capacity of ICTs to deliver information or to communicate with mass of students in somewhat entities let the process of learning more suitable for the student's need in time and place without the restrictions of the traditional classroom situations.

g. Information technology can only contribute substantially to the improvement of schooling if it is appropriately embedded in powerful and interactive learning environments [established within] the broader context of [supportive] pedagogy, curriculum and school organization (DEETYA 1996:14), when it is so embedded, the improvement could be substantial.

\section{CONCLUSION}

The use of ICTs in language teaching has countless benefits. The development in the use of ICT, like language lab, videos, satellite broadcast, videoconferencing and web seminars have support the richness and quality of education both on and off campus. The Distribution of the knowledge and learning with more flexibility supports the slogan, "Any space is a learning space." Therefore, our schools and universities should be equipped with computers and internet services not just tools to learn a language, but they contribute to different aspects of educational development and effective learning. We as African teachers should be aware of the challenges facing African education in general and ELT mainly; otherwise we will be wading in the mud of the traditional methods inefficiency if we do not exploit ICTs more effectively and efficiently to attain our goals to adjust to the best quality.

\section{REFERENCES}

[1] Castells, M. (1996). The Rise of the Network Society: The Information Age, Economy, Society and Culture. Oxford: MA: Blackwell Publishers.

[2] DEETYA (1996). Gateways: Information technology in the learning process, Canberra.

[3] Feenberg, A. (2002). Transforming technology: A critical theory revisited. Oxford: Oxford University Press.

[4] Graddol, D. (2000). The future of English: A guide to forecasting the popularity of the English language in the 21st century (2nd Edition). The British Council.

[5] Kearns P \& Papadopoulos G. (2000). Building a learning and training culture: the experience of five OECD countries, NCVER, Adelaide.

[6] Taylor, M., C. (2001). The Moment of Complexity: Emerging Network Culture. Chicago: The University of Chicago Press.

[7] UNDP, (2003). Kenya Human Development Report: Participatory Governance for Human Development (UNDP).

[8] Yagelski, R. (2005). Computers, literacy and being: Teaching with technology for a sustainable future. http://www.albany.edu/faculty/rpy95/webtext/.

\footnotetext{
AbdulMahmoud Idrees Ibrahim was born in a small village in central Sudan in 11, July, 1957. He has a Ph.D. in English Language (Applied Linguistics), Neelain University (2006),Sudan - M.A. in English and Linguistics, University of Yemen (1999)B.A. in Arts \& Education (English), University of Yemen (1997 -Professional Diploma of Education, Faculty of Education, Khartoum University (1987- Intermediate schoolteachers' Certificate, Bakht-er-Ruda Institute of Education (1981).

He has many academic contributions such as: Compiled many course-books in linguistics \& applied linguistics as well as (ESP) courses, Compiled \& instructional designed the following course-books for Open University of Sudan.- Writing skills 1 and writing skills 2. Moreover, he Instructional designed the following course books for Open University of Sudan. He participated and attended many seminars, workshops, conferences and academic sessions in the educational field and English Language Teaching inside Sudan \& abroad.

Dr. AbdulMahmoud Idrees Ibrahim-Assistant professor - Now he is the Head, English Department Language, Faculty of Education, Alza'em Alazhari University.
} 